\title{
DESEMPENHO DE SEMENTES DE PIMENTÃO REVESTIDAS COM DIFERENTES MATERIAIS ${ }^{1}$
}

\author{
JOÃO ALMIR OLIVEIRA²; CARLOS EDUARDO PEREIRA3; RENATO MENDES GUIMARÃES4; \\ ANTONIO RODRIGUES VIEIRA5; JOÃO BOSCO CARVALHO DA SILVA ${ }^{6}$
}

\begin{abstract}
RESUMO - A técnica de revestimento de sementes tem sido bastante utilizada, principalmente para as espécies que possuem sementes pequenas, como as olerícolas, forrageiras, florestais e ornamentais, pois além de aumentar o tamanho das mesmas para fins de semeadura direta, possibilita a aplicação de outros elementos essenciais ao bom desempenho da cultura em sua fase inicial. Neste contexto, o presente trabalho teve como objetivo revestir sementes de pimentão com diferentes tipos de materiais e avaliar seu comportamento durante o armazenamento. Sementes tratadas ou não com Rovrin, na dosagem de $200 \mathrm{~g} / 100 \mathrm{~kg}$, foram submetidas ao pré-condicionamento, pela embebição das sementes em solução de KNO3 a -1,1MPa, em sistema aerado por cinco dias. Após secas, as sementes foram revestidas com uma mistura de areia + microcelulose e outra de calcário + microcelulose. As sementes revestidas, juntamente com as não revestidas, foram secadas e embaladas em envelopes de papel comum (embalagem permeável) e em papel laminado (embalagem impermeável) e armazenadas em condições de ambiente no Laboratório de Análise de Sementes da UFLA. A avaliação da qualidade das sementes foi realizada a cada quatro meses, por um período de 20 meses, utilizando as seguintes determinações: teor de água, teste de germinação, envelhecimento acelerado, deterioração controlada e emergência em solo + areia. Pelos resultados obtidos, conclui-se que o revestimento de sementes reduz a velocidade, mas não afeta a taxa de germinação das sementes de pimentão antes do armazenamento; no entanto, as sementes revestidas deterioram mais rapidamente do que as não revestidas quando armazenadas em embalagem permeável. A natureza dos materiais de revestimento não influencia na qualidade das sementes de pimentão, quando armazenadas em embalagem impermeável.
\end{abstract}

Termos para indexação: revestimento, pimentão, sementes, qualidade.

\section{PERFORMANCE OF GREEN PEPPER SEEDS COVERED WITH DIFFERENT MATERIALS}

\begin{abstract}
The technique of covering seeds has been used mainly for the species which have small seeds, such as vegetables, forage, forest and ornamental species, because besides increasing the size of the seeds for direct sowing, it is possible to add other elements which are necessary for the good development of the plant in its early stages. In this context the objective of the present study was to covered green-pepper seeds in different types of materials and to evaluate their behavior during storage. Seeds treated and not treated with Rovrin at the dosage of $200 \mathrm{~g} / 100 \mathrm{~kg}$ were submitted to pre-conditioning for the imbibing of seeds in KNO3 in -1,1Mpa solution, in an aired system for 5 days. After drying the seeds were covered in a mixture of sand + microcellulose and another of limestone + microcellulose. The covered seeds and those not covered were dried and packed in paper envelopes (permeable pack) and in aluminum envelopes (impermeable pack)
\end{abstract}

\footnotetext{
${ }^{1}$ Aceito para publicação em 12/11/2003.

${ }^{2}$ Prof. Dr., UFLA, Cx. Postal 37, 37200-000, Lavras, MG; e-mail: jalmir@ufla.br

${ }^{3}$ Graduando agronomia, UFLA; e-mail: sementes@ufla.br
}

\footnotetext{
${ }^{4}$ Prof. Dr., UFLA; e-mail: renatomg@ufla.br

${ }^{5}$ Dr. Pesquisador, EPAMIG, Cx. Postal 176, 37200-000, Lavras, MG; email: arvieira@ufla.br

${ }^{6}$ Dr. Pesquisador, Embrapa; Cx. Postal 218, 70359-970, Brasília, DF; email: jbosco@cnph.embrapa.br
} 
and stored at room temperature in the Seeds Analysis Laboratory at UFLA. The seed quality was evaluated once every four months, for a period of 20 months, using the following parameters: water content, germination test, accelerated aging, controlled deterioration and emergency in soil + sand. From the results, it was possible to conclude that the covering of seeds slows but does not affect the germination rate of the green pepper seeds before storage, but the covered seeds deteriorate faster than the seeds not covered, when stored in permeable packs. The nature of the materials used did not affect the quality of the green pepper seeds stored in impermeable packs.

Index-terms: recovered, green pepper, seeds, quality.

\section{INTRODUÇÃO}

O revestimento de sementes é uma técnica usada há bastante tempo, principalmente em hortaliças, leguminosas, florestais e ornamentais, que consiste de um mecanismo de aplicação de materiais inertes e adesivos, objetivando aumentar o tamanho da semente, bem como alterar sua forma e textura para facilitar a semeadura direta. Além disso, apresenta a vantagem de possibilitar a utilização conjunta de nutrientes, fungicidas, inseticidas, herbicidas e microrganismos benéficos (Nascimento e Marton, 1993; Silva e Nakagawa, 1998 e Santos, 2000). Neste contexto, o revestimento de sementes de olerícolas tem merecido destaque, devido ao crescente aumento das áreas com semeadura direta e as caras operações de transplante.

Silva (1998) relata que o principal objetivo do recobrimento das sementes é visar a semeadura mecânica, tornando-a mais uniforme em função do aumento do tamanho, do peso e ou modificando a forma das sementes, fazendo com que estas fluam mais facilmente em uma semeadora de precisão. Além disso, Roos e Moore, 1975 relatam que há um grande interesse no uso dessas sementes para simplificar as operações de manejos em plantios manuais em hortas, casa de vegetação ou em jardins domésticos. Portanto, as sementes muito pequenas, tais como a maior parte das hortícolas, flores, gramíneas forrageiras e algumas espécies florestais, são os principais alvos deste processo de recobrimento das sementes. De qualquer forma, é necessário se ter em mente que o principal objetivo do recobrimento é o de melhorar o comportamento da semente, tanto do ponto de vista fisiológico como econômico (Sampaio e Sampaio, 1994).

Especificamente para espécies de hortícolas, o recobrimento das sementes apresenta como uma técnica de grande potencial para tornar-se viável a semeadura direta pelas seguintes razões: precisão na semeadura e no espaçamento de sementes pequenas e irregulares, redução dos custos de produção, redução de impactos que sofrem as sementes durante a semeadura, formação de um microambiente mais uni- forme ao redor das sementes no solo e economia de sementes, já que as sementes recobertas podem ser utilizadas em doses corretas pela semeadura de precisão (Roos e Moore, 1975). Alem disso há também, possibilidade de inclusão de produtos úteis como: pequenas quantidades de nutrientes, reguladores de crescimento e inoculantes e também como veículo para aplicação de inseticidas, fungicidas e repelentes de pássaros (Silva e Nakagawa, 1998, Machado 2000).

Tonkin (1979), estudando o efeito do revestimento das sementes sobre o estabelecimento das plântulas de cenoura, cebola, alface e beterraba açucareira, concluiu que, com o uso de sementes recobertas, pode-se conseguir populações ótimas, com altas taxas de emergência e com mínima utilização de mão de obra. Nesta mesma linha de pesquisa, Sachs et al. (1981) e Borderon (1989), trabalhando com sementes de fumo e begônia e com sementes compridas e pontiagudas como alface e aipo, demonstraram que o recobrimento não só atua melhorando a precisão de semeadura, como também afirmam que se trata de um método sem o qual esta técnica não seria possível.

Rodriguez Del Rinco (1988) relata que a semeadura direta, no caso do pimentão, é uma técnica de implantação do cultivo que permite obter altas populações de plantas com um custo economicamente razoável. Para reforçar a importância econômica que assume a semeadura direta na cultura do pimentão, trabalho desenvolvido por Garcia e Martin Portugues, citado por Sampaio e Sampaio (1994), mostra que aproximadamente $45 \%$ da mão de obra, empregada no cultivo extensivo do pimentão, se destina a trabalhos relacionados com a sementeira e o transplante, algo que pode ser evitado com a semeadura direta. Para o cultivo da beterraba açucareira, Antonov et al. (1978) comprovaram que, apesar de proporcionar um pequeno atraso na germinação, o recobrimento das sementes permitiu alcançar uma semeadura precisa, além de eliminar os custos com transplantes ou desbastes. Marioni (1982), comparando diferentes métodos de semeadura no cultivo de tomate e pimentão, verificou que a semeadura direta foi mais vantajosa econômicamente, prin- 
cipalmente quando se utilizam sementes híbridas que são mais caras. Também Henriksen (1987), trabalhando com sementes de cebola nesta mesma linha de pesquisa, verificou que as sementes recobertas garantem uma taxa de semeadura e uma distribuição final de plantas ao longo do sulco muito mais uniforme que as sementes desnudas. Neste sentido, Baselga (1991) relata que, pelo fato de a técnica de recobrimento conferir às sementes; tamanho, peso e forma adequada, a semeadura de precisão pode ser realizada com uma boa semeadora mecânica, não sendo imprescindível a aquisição de modernas máquinas pneumáticas, pois, além de serem caras, são exigentes em cuidados especiais para sua regulagem e manutenção.

Apesar das vantagens do revestimento das sementes no processo de semeadura, alguns materiais utilizados podem afetar sua qualidade fisiológica. Neste sentido, Sachs et al. (1981), demonstraram que a germinação de sementes de pimentão foi inibida depois de ter realizado o recobrimento. Segundo estes autores, os resultados finais indicaram a possibilidade de que altas concentrações de oxigênio são necessárias para manter um alto nível metabólico na germinação de sementes recobertas, desde o início da embebição até a elongação da radícula. Isto se pode dar, fundamentalmente pelo material de recobrimento utilizado, que, de alguma maneira, parece impedir a penetração de oxigênio para a semente. Tonkin (1979) também ressalta a importância do tipo de material utilizado no recobrimento, especificando que este não deve desintegrar-se durante a embebição formando uma massa, o que limitaria a passagem de oxigênio e, em alguns casos, da umidade para o embrião, necessária durante a germinação.

Trabalho desenvolvido por Jeong e Cho (1995), utilizando diferentes materiais para recobrimento de sementes de tomate e pimentão, possibilitou verificar que, a medida em que aumentou a concentração destes materiais, o percentual de germinação das sementes foi reduzido. Verificaram também que entre os materiais utilizados o carbonato de cálcio foi o que mostrou-se mais eficiente. Estes mesmos autores também relatam que as sementes podem ser submetidas ao processo de envigoramento (priming) antes de serem revestidas, sem, contudo afetar sua qualidade. Pereira et al. (2001), Também testando diferentes materiais no revestimento de sementes de tomate, verificaram que as sementes revestidas tiveram menor desempenho em relação às não revestidas.

Apesar do marcado incremento no uso de sementes recobertas verificado nos últimos anos, são poucas as infor- mações disponíveis na literatura sobre o comportamento destas sementes durante o período de armazenamento. Neste sentido, estudando o comportamento das sementes recobertas, Roos e Jackson (1976), trabalhando com sementes de cenoura, alface e cebola recobertas com quatro formulações comerciais, observaram que alguns materiais de cobertura parecem equilibrar-se higroscopicamente a níveis mais alto ou mais baixos de umidade relativa do ar que outros. Desta forma, estes autores alertam que, para a conservação das sementes cujos recobrimentos sejam mais hidrofílicos, é necessário que estas estejam revestidas primeiramente por materiais impermeáveis, como forma de prevenir a absorção de umidade durante o armazenamento. Outro trabalho desenvolvido por Roos (1979), com sementes de cenoura e cebola, também confirmou que o tipo de material utilizado no revestimento afetou enormemente as condições higroscópicas das sementes durante o armazenamento. Também Pereira et al. (2001), verificaram que as sementes de tomate que foram revestidas tiveram maior redução da qualidade durante o armazenamento em relação àquelas não revestidas.

Outra vantagem do revestimento de sementes é a facilidade de incorporar produtos químicos isolados ou em misturas visando o controle de patógenos, mesmo sendo incompatíveis eles podem ser adicionados em diferentes camadas do pelete ou podem ser misturados à matriz, no entanto, torna-se necessário avaliar o comportamento das sementes revestidas e que foram tratadas (Machado, 2000). Neste sentido, Pereira et al. (2001), incorporaram junto ao material de revestimento o fungicida Rovrin no tratamento de sementes de tomate e verificaram que as sementes tiveram melhor desempenho do que aquelas que foram revestidas sem o fungicida.

Desta forma, o objetivo deste trabalho foi estudar o efeito de diferentes tipos de materiais utilizados no revestimento de sementes de pimentão sobre a qualidade fisiológica inicial e durante o armazenamento das sementes, associando o tratamento fungicida.

\section{MATERIAL E MÉTODOS}

O experimento foi conduzido no laboratório de análise de sementes da Universidade Federal de Lavras - UFLA e no Centro Nacional de Pesquisa de Hortaliças (CNPH) em Brasília.

As sementes de pimentão utilizadas foram da variedade FUCHS, fornecidas pela Empresa FUCHS LTDA. Antes do revestimento, sementes tratadas ou não com Rovrim na dosa- 
gem de $200 \mathrm{~g} / 100 \mathrm{~kg}$ de sementes, foram submetidas ao condicionamento osmótico por meio de imersão em solução de KNO3 26,1g/L a -1,1Mpa, por cinco dias com sistema de aeração conforme metodologia utilizada por Roveri José (1999). Após o condicionamento as sementes foram secas em estufa de circulação de ar à temperatura de $30^{\circ} \mathrm{C}$ até atingirem umidade inicial que era de $10 \%$.

O revestimento das sementes foi realizado pelo Centro Nacional de Pesquisa de Hortaliças em Brasília, constituindo os seguintes tratamentos: Microcelulose + Calcário, Microcelulose + Areia e, como testemunha, sementes nuas ou sem revestimento. Como adesivo utilizou-se cola Cascorex - PVA na concentração de 20\%. Utilizou-se ainda um tratamento adicional com sementes não revestidas e sem priming. Após o revestimento, as sementes de cada tratamento foram secadas em estufa de circulação de ar a $35^{\circ} \mathrm{C}$ por 24 horas. Em seguida, foram embaladas em envelopes de papel comum (embalagem permeável) e em papel laminado (embalagem impermeável), considerando um envelope de cada embalagem para cada período de avaliação durante o armazenamento. As sementes embaladas foram armazenadas em condições de ambiente de Laboratório de Análise de Sementes da UFLA (média de temperatura de $24^{\circ} \mathrm{C}$ e de umidade relativa de $62 \%$ ).

A avaliação da qualidade das sementes armazenadas foi realizada a cada quatro meses por um período de 20 meses, utilizando as seguintes determinações.

1) Determinação do grau de umidade

Após cada período de armazenamento, o grau de umidade das sementes de cada tratamento em cada tipo de embalagem, foi determinado, conforme metodologia descrita pela Regras de Análise de Sementes (Brasil 1992).

\section{2) Teste de germinação}

Foram analisadas 200 sementes por tratamento, em quatro repetições de 50 sementes, semeadas sobre papel mataborrão em caixa gerbox, conforme recomendações das Regras para Análise de Sementes (Brasil, 1992). As avaliações foram realizadas diariamente, computando-se o número de sementes germinadas, ou seja, com protrusão da radícula, até a estabilização. O índice de velocidade de germinação foi calculado conforme a fórmula proposta por Maguirre (1962). No final obteve-se também o percentual de plântulas normais.
3) Teste de envelhecimento acelerado

Foram analisadas 200 sementes, utilizando o método de gerbox adaptado, sendo as sementes espalhadas em camada única sobre uma tela suspensa dentro de caixas de gerbox, contendo $40 \mathrm{ml}$ de água. Posteriormente essas caixas foram colocadas em câmara de germinação (BOD), a $42^{\circ} \mathrm{C}$ por $48 \mathrm{~h}$. Após este período as sementes foram colocadas para germinar conforme metodologia descrita para o teste de germinação. Nas avaliações, foram computadas apenas as plântulas normais.

\section{4) Emergência em bandeja}

Neste teste também foram analisadas 200 sementes, semeadas em quatro bandejas plásticas, contendo como substrato solo + areia na proporção em volume de 1:1. Após a semeadura as bandejas foram acondicionadas em câmara de crescimento vegetal, sob regime alternado de luz e escuro, a $25^{\circ} \mathrm{C}$, por 15 dias. As avaliações foram realizadas diariamente, computando-se o número de plântulas emergidas até a estabilização do estande, onde foi obtido o tempo necessário para que ocorressem 50\% de plântulas emergidas (T50). Foi também computado o estande aos 15 dias.

\section{5) Deterioração Controlada}

Neste teste também foram analisadas 200 sementes; a metodologia adotada foi a recomendada pelo Manual de Vigor da ISTA (ISTA, 1995). Após conhecer a umidade de cada amostra, as sementes foram acondicionadas em envelope impermeável adicionando-se com auxílio de uma pipeta certa quantidade de água suficiente para que elas atingissem $24 \%$ de umidade. Em seguida os envelopes contendo as sementes foram lacrados e mantidos à temperatura de $45^{\circ} \mathrm{C}$ por 24 horas. Após este período as sementes foram submetidas ao teste de germinação, avaliando o percentual de plântulas normais.

6) Delineamento estatístico

O delineamento foi inteiramente ao acaso em esquema fatorial 3x2x $6+1$, sendo três tipos de materiais de revestimento (areia + microcelulose, calcário +microcelulose e sementes não revestidas), tratadas e não tratadas com Rovrin e seis épocas de armazenamento ( $0,4,8,12,16$ e 20 meses) e um tratamento adicional (sementes sem priming e não revestidas), com quatro repetições. Os dados foram analisados pelo estudo de regressão. 


\section{RESULTADOS E DISCUSSÃO}

Pelos resultados obtidos na determinação do grau de umidade das sementes de pimentão durante o armazenamento, não houve alterações no teor de água para as sementes armazenadas em embalagem impermeável permanecendo com umidade entre 5 e $6 \%$ já as sementes armazenadas em embalagem permeável a variação entre tratamentos foi de 9,8 a $10,6 \%$ durante todo o período. No entanto, pelo teste de germinação e de vigor, observa-se que houve uma redução da qualidade das sementes ao longo do armazenamento quando estas foram armazenadas em embalagem permeável, independente do tipo de revestimento. Resultados semelhantes foram também obtidos por Pereira et al. (2001), com sementes de tomate, utilizando os mesmos materiais de revestimento.

Nota-se ainda que no início do armazenamento as diferenças de qualidade entre as sementes revestidas e não revestidas não foram significativas. Entretanto, durante o período de armazenamento, a redução da qualidade daquelas revestidas foi maior do que as não revestidas. Estes resultados estão de acordo com Roos e Jackson (1976), Roos (1979), Silva (1997) e Silva, Nakagawa (1998) e Pereira (2001), os quais também verificaram que o revestimento de sementes pode reduzir o potencial de armazenamento das mesmas. Dentre as sementes não revestidas aquelas que não foram submetidas ao priming mantiveram a sua qualidade mesmo após os 20 meses de armazenamento (tratamento adicional), comprovando que o condicionamento osmótico das sementes pode reduzir o seu potencial de armazenamento, conforme relatado por Jeong e Cho (1995).

Observa-se ainda pelos resultados do T50 (Figura 4) e do índice de velocidade de germinação (Figura 2) que houve germinação mais lenta das sementes revestidas quando comparadas com as não revestidas, independentes do tipo de material utilizado. Estes resultados corroboram com aqueles obtidos por Sampaio e Sampaio (1994), Jeong e Cho (1995) e Pereira et al. (2001), os quais também relatam que o revestimento reduz a velocidade de germinação das sementes por formar uma barreira física. Pelos resultados do teste de emer- gência em bandeja (Figura 6), nota-se que as sementes que foram revestidas com calcário + microcelulose tiveram uma maior redução do estande ao longo do armazenamento, em relação àquelas revestidas com areia + microcelulose, no entanto para os demais testes essa diferença não foi verificada. Também Silva (1997) e Pereira et al. (2001) verificaram que o uso de calcário no revestimento dificultou a germinação de sementes de tomate.

Pelos resultados do teste de germinação e vigor para as sementes que foram revestidas e armazenadas em embalagem impermeável, observa-se que a redução da qualidade após 20 meses de armazenamento foi menor em relação às sementes armazenadas em embalagem permeável. Observa-se também que houve uma maior redução da qualidade das sementes nas avaliações aos oito e doze meses de armazenamento, seguida de uma tendência crescente na qualidade, principalmente nas sementes que foram revestidas e armazenadas em embalagem impermeável. Esta tendência de redução da qualidade entre oito e doze meses do armazenamento, provavelmente tenha ocorrido devido à indução de dormência secundaria promovida pela interação do material de revestimento com a impermeabilidade da embalagem. Verifica-se ainda pelos resultados do teste de germinação (Figura 1) aos 20 meses de armazenamento, para este tipo de embalagem, que independente do tipo de tratamento, as sementes praticamente mantiveram sua qualidade inicial.

Verifica-se ainda pelos resultados do teste de deterioração controlada (Figura 5) e pelo teste de envelhecimento acelerado (Figura 3) que a maior redução do vigor ocorreu nas sementes tratadas e revestidas tanto com calcário quanto areia. Provavelmente isto ocorreu devido o efeito fitotóxico do produto fungicida durante a execução do teste, pois de acordo com as recomendações para execução deste teste as sementes não devem ser tratadas antes (ISTA, 1995). Já pelos resultados do teste de emergência em bandejas (Figura 6), verifica-se que o tratamento fungicida não influenciou o estande, havendo influência apenas do material de revestimento, uma vez que as sementes revestidas com calcário apresentaram maior redução na qualidade. 


$$
\begin{array}{ll}
\mathrm{y}_{\text {NT/NR }}=100,422-0,578 \mathrm{x} & \mathrm{R}^{2}=77,6 \% * \\
\mathrm{y}_{\mathrm{NT} / \mathrm{A}}=95,714-2,096 \mathrm{x} & \mathrm{R}^{2}=79,7 \% * \\
\mathrm{y}_{\mathrm{NT} / \mathrm{C}}=93,643-1,589 \mathrm{x} & \mathrm{R}^{2}=86,4 \% * \\
\mathrm{y}_{\mathrm{T} / \mathrm{NR}}=103,595-1,343 \mathrm{x} & \mathrm{R}^{2}=72,3 \% * \\
\mathrm{y}_{\mathrm{T} / \mathrm{A}}=96,405-1,857 \mathrm{x} & \mathrm{R}^{2}=77,7 \%^{*} \\
\mathrm{y}_{\mathrm{T} / \mathrm{C}}=103,405-2,282 \mathrm{x} & \mathrm{R}^{2}=77,2 \% * \\
\mathrm{y}_{\text {ADICIONAL }}=\text { não significativo } &
\end{array}
$$

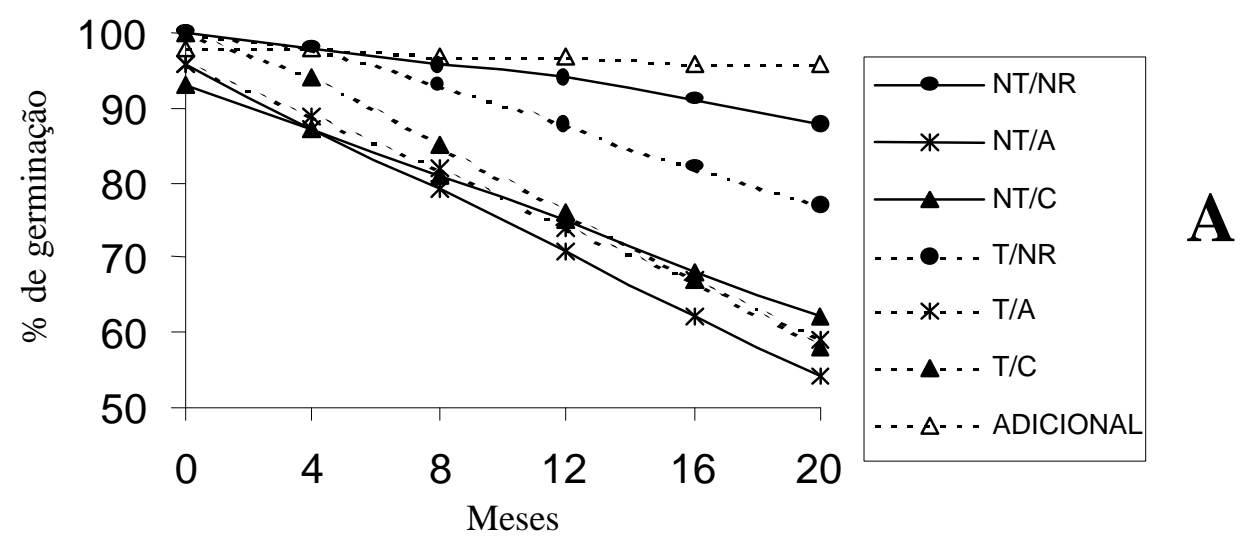

$$
\begin{array}{ll}
\mathrm{y}_{\mathrm{NT} / \mathrm{NR}}=97,857-0,111 \mathrm{x} & \mathrm{R}^{2}=83,8 \% * \\
\mathrm{y}_{\mathrm{NT/A}}=\text { não significativo } & \\
\mathrm{y}_{\mathrm{NT/C}}=95,214-1,909 \mathrm{x}+0,109 \mathrm{x}^{2} & \mathrm{R}^{2}=77,8 \% * \\
\mathrm{y}_{\mathrm{T} / \mathrm{NR}}=100,089-1,064 \mathrm{x}+0,044 \mathrm{x}^{2} & \mathrm{R}^{2}=73,0 \% * \\
\mathrm{y}_{\mathrm{T} / \mathrm{A}}=96,659+0,161 \mathrm{x}-0,140 \mathrm{x}^{2}+0,007 \mathrm{x}^{3} & \mathrm{R}^{2}=68,9 \% * \\
\mathrm{y}_{\mathrm{T} / \mathrm{C}}=96,847+3,691 \mathrm{x}-0,988 \mathrm{x}^{2}+0,077 \mathrm{x}^{3}-0,002 \mathrm{x}^{4} & \mathrm{R}^{2}=81,6 \% *
\end{array}
$$

$\mathrm{y}_{\text {ADICIONAL }}=$ não significativo

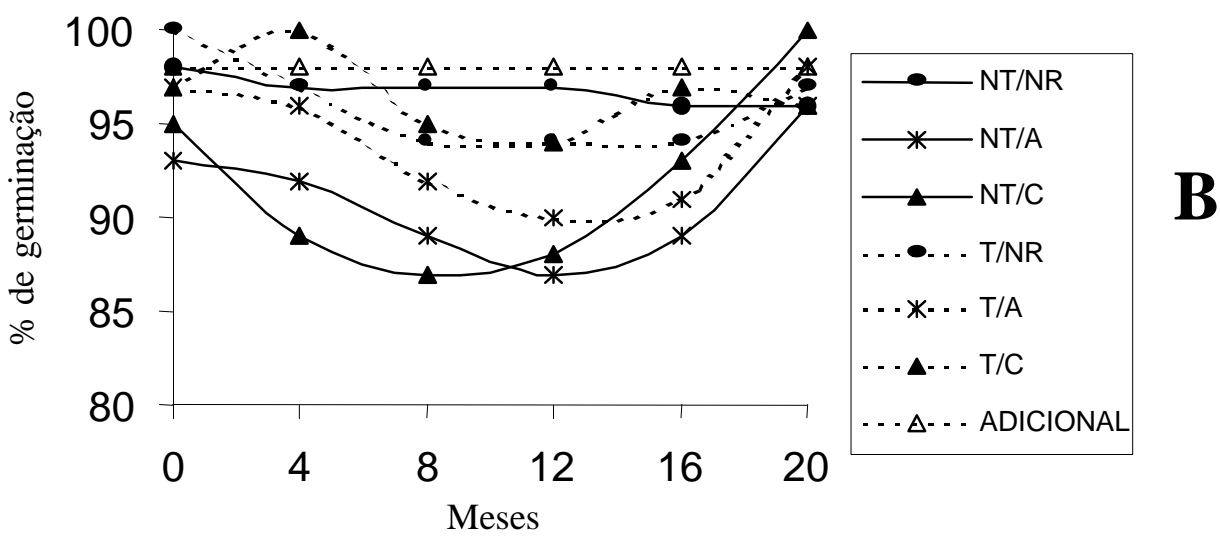

FIG. 1. Resultados médios de germinação de sementes de pimentão revestidas com areia (A), calcário (C), não revestidas (NR), tratadas (T) e não tratadas (NT) e armazenadas em embalagem permeável (A) e impermeável (B). UFLA, Lavras, MG. 2002. 


$$
\begin{array}{ll}
\mathrm{y}_{\mathrm{NTNR}}=16,441-0,532 \mathrm{x} & \mathrm{R}^{2}=85,7 \% * \\
\mathrm{y}_{\mathrm{NT} / \mathrm{A}}=6,739-0,237 \mathrm{x} & \mathrm{R}^{2}=77,8 \% * \\
\mathrm{y}_{\mathrm{NT} / \mathrm{C}}=6,721-0,229 \mathrm{x} & \mathrm{R}^{2}=84,8 \% * \\
\mathrm{y}_{\mathrm{T} / \mathrm{NR}}=21,977-0,659 \mathrm{x} & \mathrm{R}^{2}=75,2 \% * \\
\mathrm{y}_{\mathrm{T} / \mathrm{A}}=11,079-0,399 \mathrm{x} & \mathrm{R}^{2}=80,0 \% * \\
\mathrm{y}_{\mathrm{T} / \mathrm{C}}=9,034-0,291 \mathrm{x} & \mathrm{R}^{2}=72,3 \% * \\
\mathrm{y}_{\text {ADICIONAL }}=10,941-0,307 \mathrm{x} & \mathrm{R}^{2}=80,5 \% *
\end{array}
$$

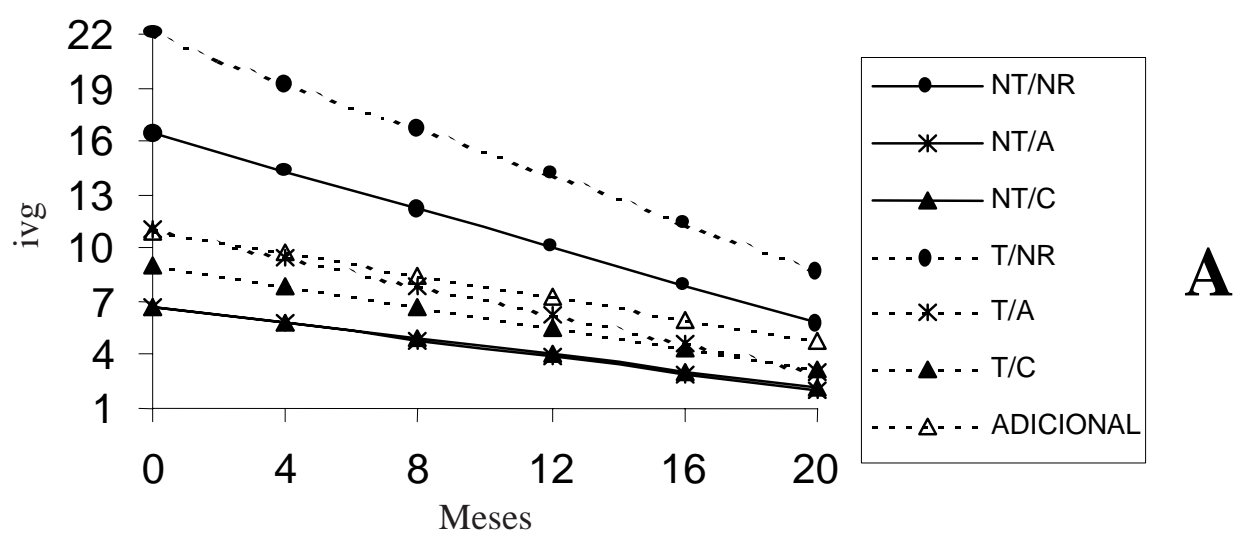

$$
\begin{array}{ll}
\mathrm{y}_{\text {NT/NR }}=17,054-1,451 \mathrm{x}+0,224 \mathrm{x}^{2}-0,008 \mathrm{x}^{3} & \mathrm{R}^{2}=88,2 \% * \\
\mathrm{y}_{\text {NT/A }}=5,286+1,542 \mathrm{x}-0,325 \mathrm{x}^{2}+0,024 \mathrm{x}^{3}-0,001 \mathrm{x}^{4} & \mathrm{R}^{2}=85,7 \% * \\
\mathrm{y}_{\text {NT/C }}=6,377+0,133 \mathrm{x} & \mathrm{R}^{2}=74,6 \% * \\
\mathrm{y}_{\mathrm{T} / \mathrm{NR}}=22,351-2,471 \mathrm{x}+0,229 \mathrm{x}^{2}-0,006 \mathrm{x}^{3} & \mathrm{R}^{2}=75,2 \% * \\
\mathrm{y}_{\mathrm{T} / \mathrm{A}}=10,384+1,244 \mathrm{x}-0,411 \mathrm{x}^{2}+0,037 \mathrm{x}^{3}-0,001 \mathrm{x}^{4} & \mathrm{R}^{2}=71,9 \% * \\
\mathrm{y}_{\mathrm{T} / \mathrm{C}}=8,310+0,481 \mathrm{x}-0,017 \mathrm{x}^{2} & \mathrm{R}^{2}=71,9 \% * \\
\mathrm{y}_{\text {ADICIONAL }}=10,888+0,361 \mathrm{x}-0,193 \mathrm{x}^{2}+0,021 \mathrm{x}^{3}-0,001 \mathrm{x}^{4} & \mathrm{R}^{2}=91,2 \% *
\end{array}
$$

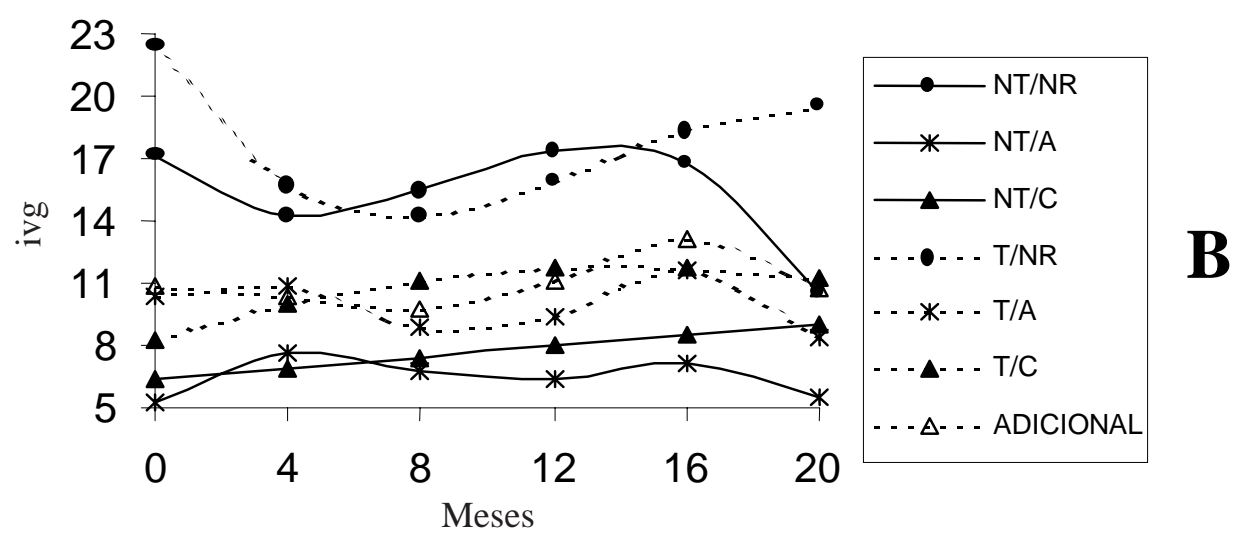

FIG. 2. Resultados médios do índice de velocidade de germinação de sementes de pimentão revestidas com com areia (A), calcário (C), não revestidas (NR), tratadas (T) e não tratadas (NT) e armazenadas em embalagem permeável (A) e impermeável (B). UFLA, Lavras, MG. 2002. 


$\begin{array}{ll}\mathrm{y}_{\text {NT/NR }}=97,762-0,593 \mathrm{x} & \mathrm{R}^{2}=72,4 \% * \\ \mathrm{y}_{\text {NT/A }}=89,500-1,925 \mathrm{x} & \mathrm{R}^{2}=81,9 \% * \\ \mathrm{y}_{\text {NT/C }}=91,548-2,221 \mathrm{x} & \mathrm{R}^{2}=74,7 \% * \\ \mathrm{y}_{\mathrm{T} / \mathrm{NR}}=100,548-1,396 \mathrm{x} & \mathrm{R}^{2}=89,9 \% * \\ \mathrm{y}_{\mathrm{T} / \mathrm{A}}=97,667-2,741 \mathrm{x} & \mathrm{R}^{2}=88,0 \% * \\ \mathrm{y}_{\text {T/C }}=83,310-1,989 \mathrm{x} & \mathrm{R}^{2}=72,5 \% * \\ \mathrm{y}_{\text {ADICIONAL }}=99,137-0,818 \mathrm{x} & \mathrm{R}^{2}=85,9 \% *\end{array}$

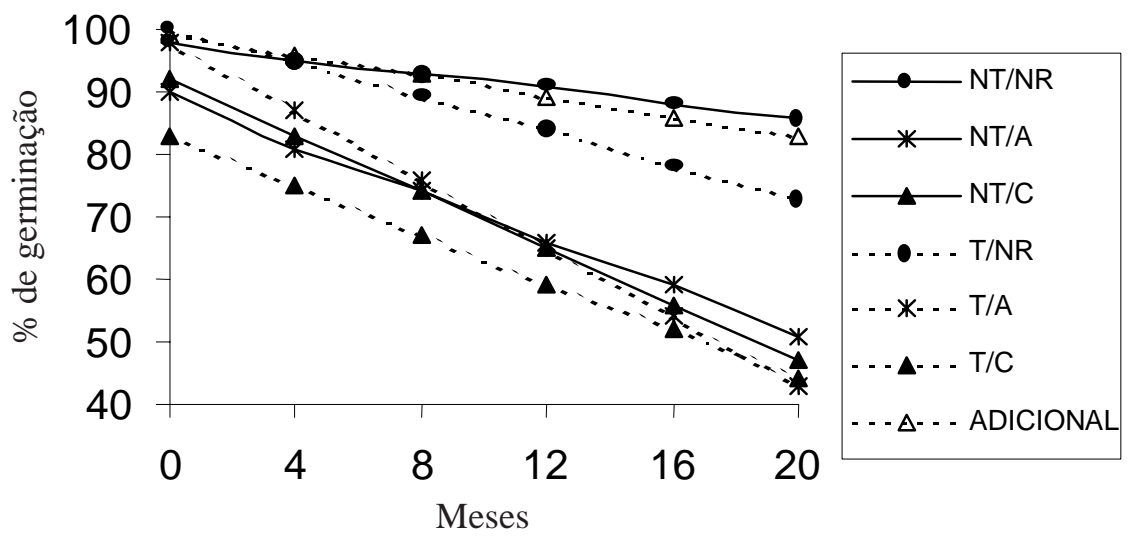

$$
\begin{array}{ll}
\mathrm{y}_{\mathrm{NT} / \mathrm{NR}}=96,552+0,362 \mathrm{x}-0,123 \mathrm{x}^{2}+0,005 \mathrm{x}^{3} & \mathrm{R}^{2}=72,5 \% * \\
\mathrm{y}_{\mathrm{NT} / \mathrm{A}}=95,036-2,517 \mathrm{x}+0,106 \mathrm{x}^{2} & \mathrm{R}^{2}=81,8 \% * \\
\mathrm{y}_{\mathrm{NT} / \mathrm{C}}=94,167-0,725 \mathrm{x} & \mathrm{R}^{2}=80,1 \% * \\
\mathrm{y}_{\mathrm{T} / \mathrm{NR}}=96,167-0,350 \mathrm{x} & \mathrm{R}^{2}=74,6 \% * \\
\mathrm{y}_{\mathrm{T} / \mathrm{A}}=94,105+9,935 \mathrm{x}-3,209 \mathrm{x}^{2}+0,269 \mathrm{x}^{3}-0,007 \mathrm{x}^{4} & \mathrm{R}^{2}=82,9 \% * \\
\mathrm{y}_{\mathrm{T} / \mathrm{C}}=87,071+2,089 \mathrm{x}-0,138 \mathrm{x}^{2} & \mathrm{R}^{2}=71,8 \% *
\end{array}
$$

$\mathrm{y}_{\text {ADICIONAL }}=$ não significativo

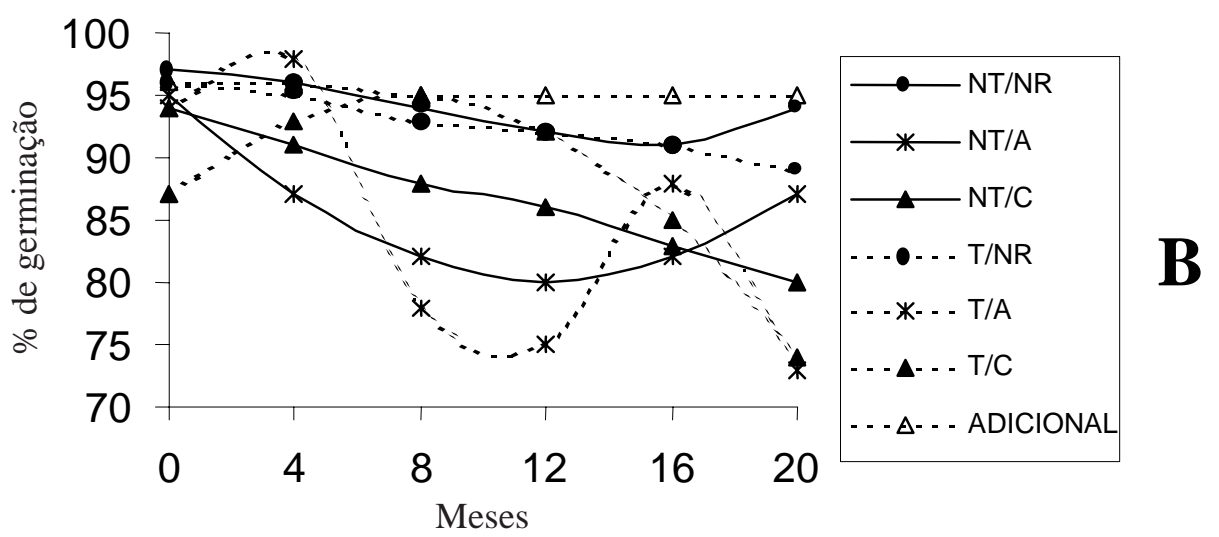

FIG. 3. Resultados médios de germinação após envelhecimento das sementes de pimentão revestidas com areia (A), calcário (C), não revestidas (NR), tratadas (T) e não tratadas (NT) e armazenadas em embalagem permeável (A) e impermeável (B). UFLA, Lavras, MG. 2002. 


$$
\begin{array}{ll}
\mathrm{y}_{\text {NT/NR }}=8,155-0,436 \mathrm{x}+0,068 \mathrm{x}^{2}-0,002 \mathrm{x}^{3} & \mathrm{R}^{2}=81,9 \% * \\
\mathrm{y}_{\mathrm{NT/A}}=8,356+0,269 \mathrm{x} & \mathrm{R}^{2}=76,4 \% * \\
\mathrm{y}_{\mathrm{NT/C}}=8,630+0,280 \mathrm{x} & \mathrm{R}^{2}=79,4 \% * \\
\mathrm{y}_{\mathrm{T} / \mathrm{NR}}=7,133+0,130 \mathrm{x} & \mathrm{R}^{2}=80,1 \% * \\
\mathrm{y}_{\mathrm{T} / \mathrm{A}}=7,602+0,270 \mathrm{x} & \mathrm{R}^{2}=87,4 \% * \\
\mathrm{y}_{\mathrm{T} / \mathrm{C}}=7,203+0,366 \mathrm{x} & \mathrm{R}^{2}=88,2 \% * \\
\mathrm{y}_{\text {ADICIONAL }}=\text { não significativo } &
\end{array}
$$

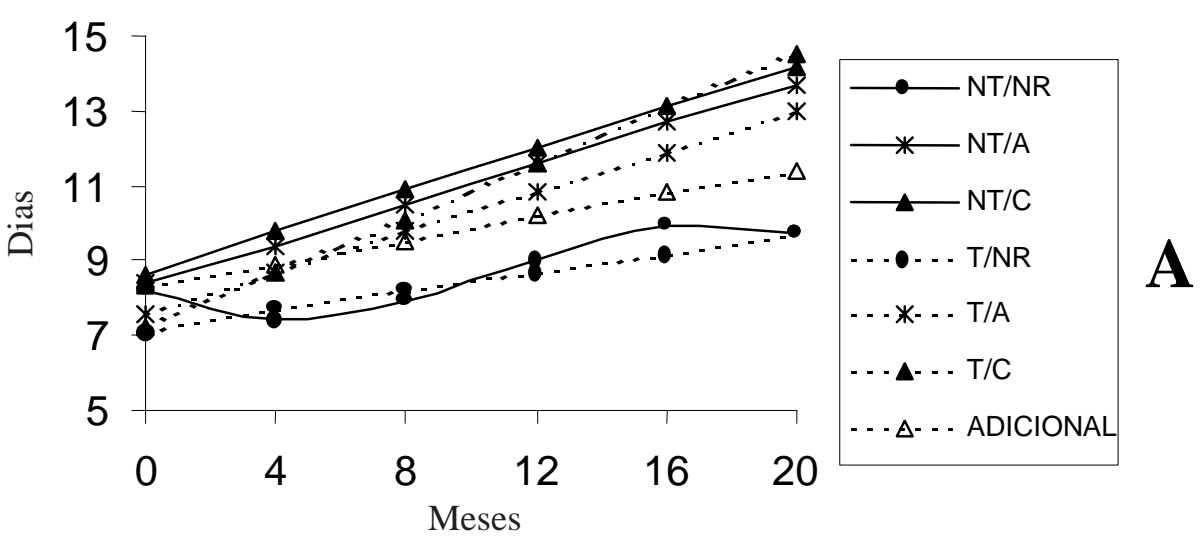

$\mathrm{y}_{\mathrm{NT} / \mathrm{NR}}=$ não significativo

$$
\begin{array}{ll}
\mathrm{y}_{\mathrm{NT} / \mathrm{A}}=9,293-0,105 \mathrm{x}+0,004 \mathrm{x}^{2} & \mathrm{R}^{2}=82,6 \% * \\
\mathrm{y}_{\mathrm{NT} / \mathrm{C}}=10,059-0,414 \mathrm{x}+0,043 \mathrm{x}^{2}-0,001 \mathrm{x}^{3} & \mathrm{R}^{2}=75,6 \% * \\
\mathrm{y}_{\mathrm{T} / \mathrm{NR}}=7,187+0,148 \mathrm{x}-0,011 \mathrm{x}^{2} & \mathrm{R}^{2}=70,0 \% *
\end{array}
$$

$\mathrm{y}_{\mathrm{T} / \mathrm{A}}=$ não significativo

$\mathrm{y}_{\mathrm{T} / \mathrm{C}}=$ não significativo

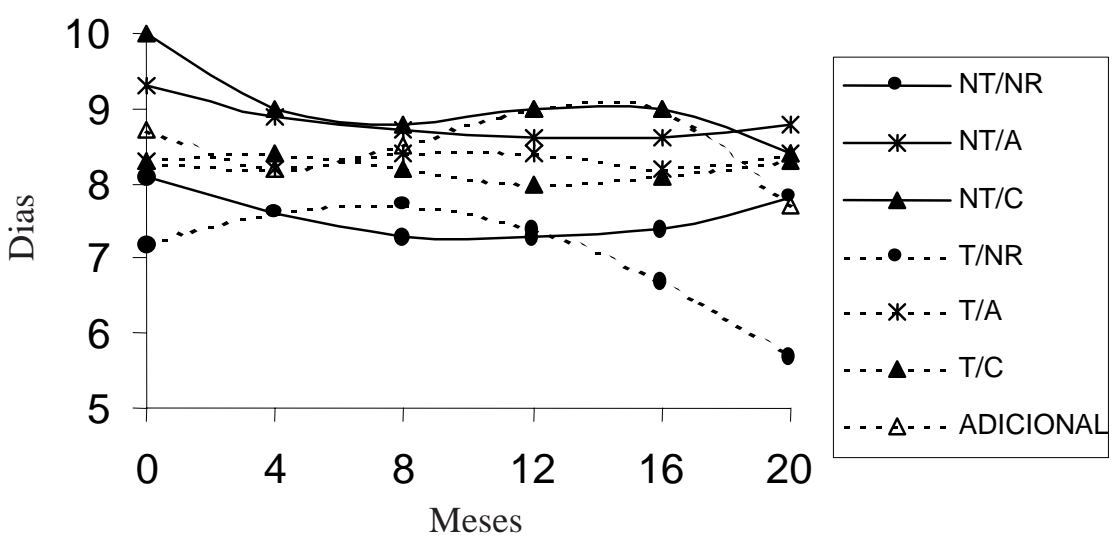

B

FIG. 4. Resultados médios do número de dias gastos para a emergência de $50 \%$ (T50) de sementes de pimentão revestidas com areia (A), calcário (C), não revestidas (NR), tratadas (T) e não tratadas (NT) e armazenadas em embalagem permeável (A) e impermeável (B). UFLA, Lavras-MG. 2002. 


$$
\begin{array}{ll}
\mathrm{y}_{\mathrm{NT} / \mathrm{NR}}=103,262-1,718 \mathrm{x} & \mathrm{R}^{2}=88,1 \% * \\
\mathrm{y}_{\mathrm{NT} / \mathrm{A}}=95,548-3,621 \mathrm{x} & \mathrm{R}^{2}=78,5 \% * \\
\mathrm{y}_{\mathrm{NT} / \mathrm{C}}=93,667-3,850 \mathrm{x} & \mathrm{R}^{2}=86,6 \% * \\
\mathrm{y}_{\mathrm{T} / \mathrm{NR}}=101,643-2,289 \mathrm{x} & \mathrm{R}^{2}=96,4 \% * \\
\mathrm{y}_{\mathrm{T} / \mathrm{A}}=90,429-3,418 \mathrm{x} & \mathrm{R}^{2}=81,4 \% * \\
\mathrm{y}_{\mathrm{T} / \mathrm{C}}=81,024-3,561 \mathrm{x} & \mathrm{R}^{2}=88,8 \% * \\
\mathrm{y}_{\text {ADICIONAL }}=96,981-2,354 \mathrm{x}+0,261 \mathrm{x}^{2}-0,009 \mathrm{x}^{3} & \mathrm{R}^{2}=75,3 \% *
\end{array}
$$

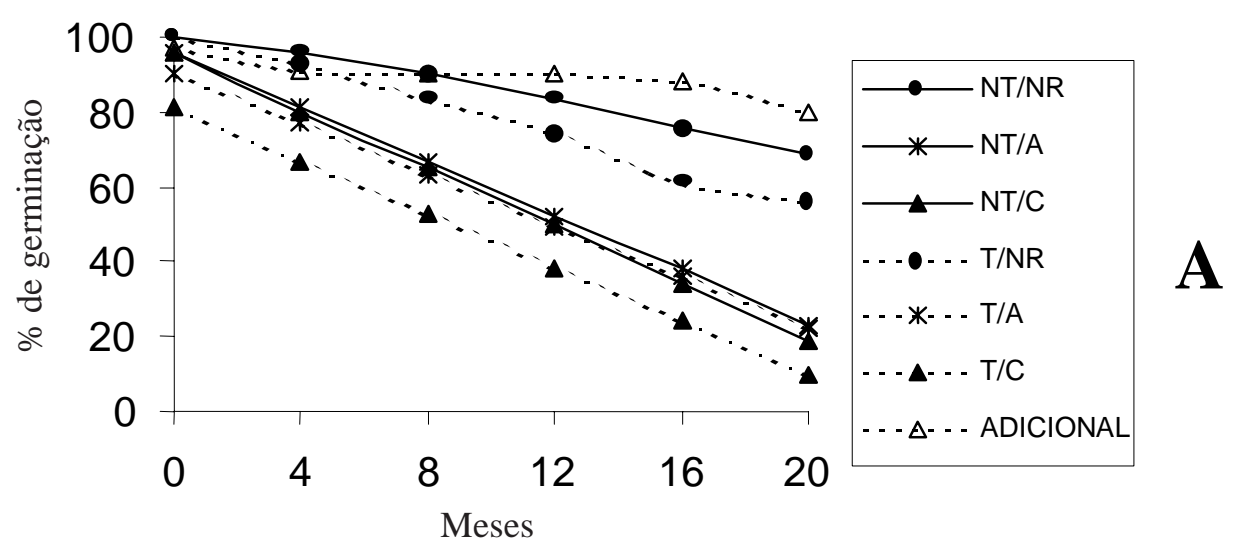

$$
\begin{array}{ll}
\mathrm{y}_{\text {NT/NR }}=98,548-0,696 \mathrm{x} & \mathrm{R}^{2}=71,2 \% * \\
\mathrm{y}_{\mathrm{NT} / \mathrm{A}}=\text { não significativo } & \\
\mathrm{y}_{\mathrm{NT/C}}=82,710+9,922 \mathrm{x}-2,799 \mathrm{x}^{2}-0,222 \mathrm{x}^{3}-0,005 \mathrm{x}^{4} & \mathrm{R}^{2}=80,2 \% * \\
\mathrm{y}_{\mathrm{T} / \mathrm{NR}}=97,095-1,018 \mathrm{x} & \mathrm{R}^{2}=78,9 \% * \\
\mathrm{y}_{\mathrm{T} / \mathrm{A}}=80,012+8,875 \mathrm{x}-2,997 \mathrm{x}^{2}+0,250 \mathrm{x}^{3}-0,006 \mathrm{x}^{4} & \mathrm{R}^{2}=66,2 \% * \\
\mathrm{y}_{\mathrm{T} / \mathrm{C}}=74,637+6,302 \mathrm{x}-2,023 \mathrm{x}^{2}+0,180 \mathrm{x}^{3}-0,005 \mathrm{x}^{4} & \mathrm{R}^{2}=71,7 \% * \\
\mathrm{y}_{\text {ADICIONAL }}=95,965+2,431 \mathrm{x}-0,929 \mathrm{x}^{2}+0,085 \mathrm{x}^{3}-0,002 \mathrm{x}^{4} & \mathrm{R}^{2}=81,1 \% *
\end{array}
$$

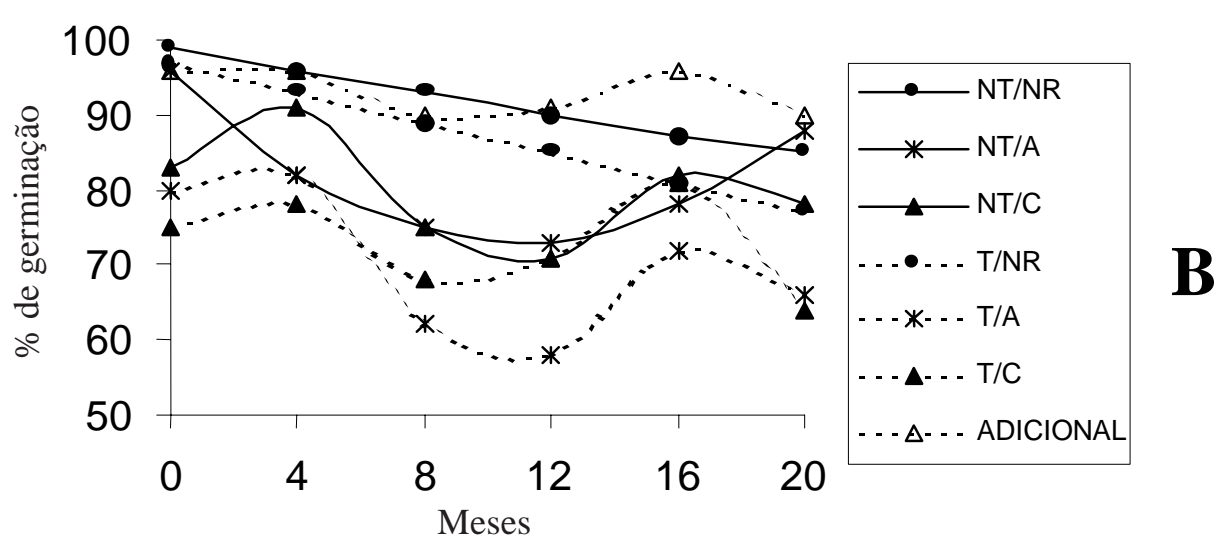

FIG. 5. Resultados médios de germinação após o teste de deterioração controlada de sementes de pimentão revestidas com areia (A), calcário (C), não revestidas (NR), tratadas (T) e não tratadas (NT) e armazenadas em embalagem permeável (A) e impermeável (B). UFLA, Lavras, MG. 2002. 


$$
\begin{array}{ll}
\mathrm{y}_{\mathrm{NT} / \mathrm{NR}}=104,095-1,368 \mathrm{x} & \mathrm{R}^{2}=76,0 \% * \\
\mathrm{y}_{\mathrm{NT} / \mathrm{A}}=105,071-3,057 \mathrm{x} & \mathrm{R}^{2}=81,5 \% * \\
\mathrm{y}_{\mathrm{NT/C}}=90,024-3,323 \mathrm{x} & \mathrm{R}^{2}=89,4 \% * \\
\mathrm{y}_{\mathrm{T} / \mathrm{NR}}=103,071-1,582 \mathrm{x} & \mathrm{R}^{2}=79,1 \% * \\
\mathrm{y}_{\mathrm{T} / \mathrm{A}}=105,357-3,223 \mathrm{x} & \mathrm{R}^{2}=86,9 \% * \\
\mathrm{y}_{\mathrm{T} / \mathrm{C}}=98,488-3,657 \mathrm{x} & \mathrm{R}^{2}=87,4 \% * \\
\mathrm{y}_{\text {ADICIONAL }}=99,679-0,405 \mathrm{x} & \mathrm{R}^{2}=89,0 \% *
\end{array}
$$

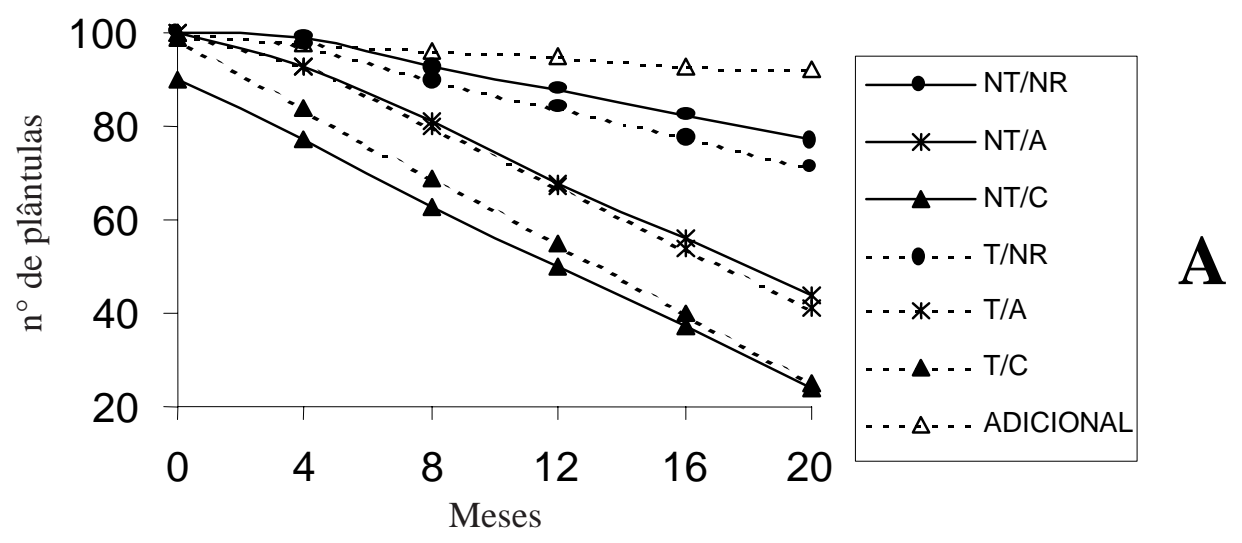

$$
\begin{array}{ll}
\mathrm{y}_{\mathrm{NT}}=93,599-0,374 \mathrm{x} & \mathrm{R}^{2}=80,9 \% * \\
\mathrm{y}_{\mathrm{T}}=94,738-0,353 \mathrm{x} & \mathrm{R}^{2}=85,4 \% * \\
\mathrm{y}_{\mathrm{NR}}=\text { não significativo } & \\
\mathrm{y}_{\mathrm{A}}=96,155-0,507 \mathrm{x} & \mathrm{R}^{2}=75,2 \% * \\
\mathrm{y}_{\mathrm{C}}=86,875+0,371 \mathrm{x}-0,048 \mathrm{x}^{2} & \mathrm{R}^{2}=78,0 \% * \\
\mathrm{y}_{\text {ADICIONAL }}=98,842-3,272 \mathrm{x}+0,983 \mathrm{x}^{2}-0,091 \mathrm{x}^{3}+0,003 \mathrm{x}^{4} & \mathrm{R}^{2}=71,1 \% *
\end{array}
$$

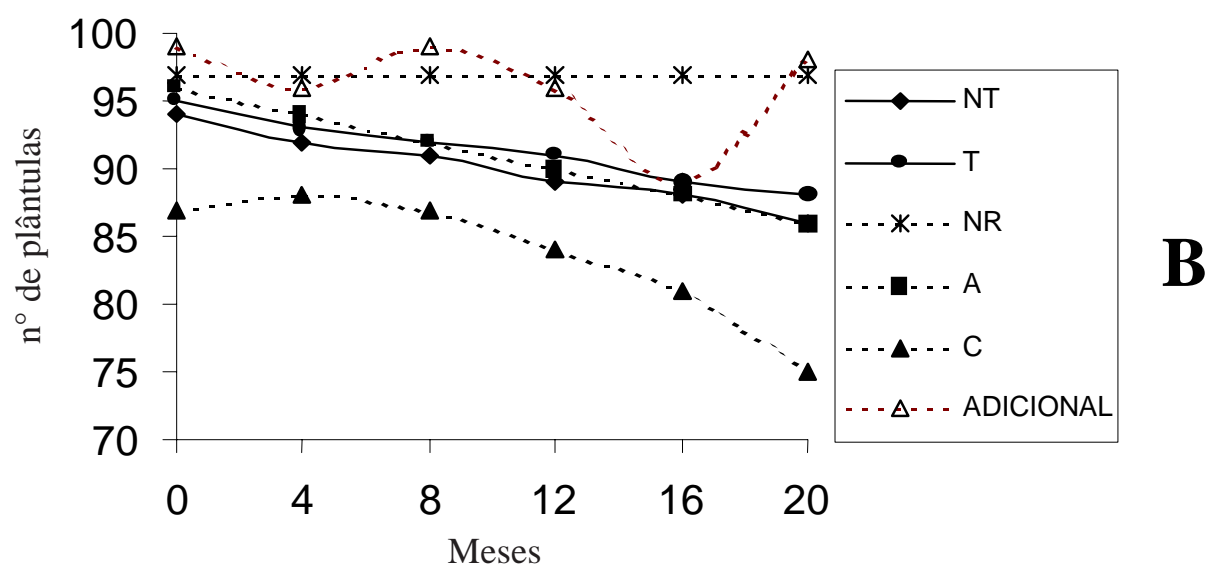

FIG. 6. Resultados médios (\%) de plântulas obtidas no teste de emergência em bandeja com sementes de pimentão revestidas com areia (A), calcário (C), não revestidas (NR), tratadas (T) e não tratadas (NT) e armazenadas em embalagem permeável (A) e impermeável (B). UFLA, Lavras, MG. 2002. 


\section{CONCLUSÕES}

Pela metodologia utilizada no presente trabalho, podese concluir que:

- o revestimento de sementes reduz a velocidade, mas não afeta a taxa de germinação das sementes de pimentão antes do armazenamento;

- sementes revestidas deterioram mais rapidamente do que as não revestidas quando armazenadas em embalagem permeável;

- a natureza dos materiais de revestimento não influencia na qualidade das sementes de pimentão;

- é possível armazenar sementes revestidas de pimentão em embalagem impermeável.

\section{REFERÊNCIAS}

ANTONOV, I.; SLAVOV, K.; PURVANOV, P.; STANCHEV, S. Pelleting of sugar beet seed and of some other crops. Plant Science.,15, 32-36, 1978.

BASELGA, J.A.E. Remolacha azucarera. Nuevas técnicas de cultivo. III Symposium Nascional de Semillas. Sevilla. 93-100, 1991.

BORDERON, M.A. Semences de cereales: le pelliculage cagne du terrain. Cultivar, 253, 34-35, 1989.

BRASIL, Minsitério da Agricultura e Reforma Agrária. Regras para Análise de Sementes, Brasília, 1992, 365p.

HENRIKSEN, K. Seed type and sowing techniques for onion. Horticience abstract. 57, 2631987.

ISTA, Internacional Seed Testing Association. Handbook of vigour test methods. Zurick: 1995. 117P

JEONG, Y.O.; CHO, J.L. Effect of coating materials and priming on seed germination of tomato and pepper. Journal of the Koreano for Horticultural Science. Korean. V.36, n.2, 185-191, 1995.

MACHADO, J. da C. Tratamento de sementes no controle de doenças. Lavras: LAPS/UFLA/FAEPE, 2000, 138p.

MAGUIRRE, J.D. Spped og germination aid in selection and evaluation for seedling and vigour. Crop Science, Madison, v.2,n.2, p.176-177, Mar./Apr. 1962
MARIONI, L. The development of planting techniques for tomatoes and Capsicums in the Tuscan Maremma. Notiziario di Ortoflorofruticoltura, 8, 123-130, 1982.

NASCIMENTO, W.M.; SILVA, J.B.C.; MARTON, L. Qualidade fisiológica de sementes peletizadas de tomate durante o armazenamento. Informativo ABRATES, v.3, n.3, p.47, jun 1993.

PEREIRA, C.E.; OLIVEIRA, J.A.; SILVA, J.B.C.; RESENDE, M.L. Desempenho de sementes de tomate revestidas com diferentes materiais. IN: Congresso de Olericultura, Brasília. Revista da Sociedade de Olericultura do Brasil. Brasília, v19, n.1, p.286, 2001.

RODRIGUEZ DEL RINCO, A. Condiciones para la Siembra Directa del Pimiento. Mesa Redonda: Siembra Directa de Pimiento. INIA, Madrid, 13-16, 1988.

ROOS, E.E.; JACKSON, G.S. Testing coated seed: Germination and moisture absorption properties. Journal Seed Technology, 1 , 86-95, 1976.

ROOS, E.E. Germination of pelleted and taped carrotand onion seed following storage. Journal Seed Technology, 4, 65-78, 1979.

ROOS, E.E.; MOORE, F.D. Effect of seed coating performance of lettuce seeds in greenhouse soil tests. Journal Amer. Soc. Hort. Sci., 100, 573-576, 1975.

ROVERI JOSÉ, S.C.B. Condicionamento osmótico de sementes de pimentão: Efeito na Germinação, vigor e atividade enzimática, UFLA- Lavras, 107p, 1999. (Dissertação de mestrado)

SACHS, M.; CANTLIFFE, D.J.; NELL, T.A. Germination studies of clay-coated sweet pepper seeds. Journal Am. Hort. Science, 106, 385-389, 1981.

SAMPAIO, T.G.; SAMPAIO, N.V. Recobrimento de sementes trabalhos técnicos. Informativo ABRATES, Brasília, v.4, n.3, 20-52 dez. 1994.

SANTOS, P. E.C.; SILVA, J.B.C.; NASCIMENTO, W.M. avaliação de materiais para peletização de sementes de alface. Horticultura Brasileira, v.18, Suplemento julho, p.1036-7, 2000.

SILVA, J.B.C. Avaliação de métodos e materiais para a peletização de sementes, UNESP-Botucatu, 189p, 1997. (Tese de Doutorado)

SILVA, J.B.C.; NAKAGAWA, J. Confecção e avaliação de péletes de sementes de alface, Horticultura Brasileira, v.16, n.2, p.151158, 1998.

TONKIN, J.H.B. Pelleting and other presowing treatments. Advances Seed Technology, 4, 84-105, 1979.

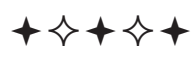

